\title{
Spatio-temporal analysis of abundances of three malaria vector species in southern Benin using zero-truncated models
}

\author{
Nicolas Moiroux ${ }^{1 *}$, Armel Djènontinn $^{2,3}$, Abdul S Bio-Bangana $^{3}$, Fabrice Chandre ${ }^{1}$, Vincent Corbel ${ }^{1,4}$ \\ and Hélène Guis ${ }^{5,6}$
}

\begin{abstract}
Background: A better understanding of the ecology and spatial-temporal distribution of malaria vectors is essential to design more effective and sustainable strategies for malaria control and elimination. In a previous study, we analyzed presence-absence data of An. funestus, An. coluzzii, and An. gambiae s.s. in an area of southern Benin with high coverage of vector control measures. Here, we further extend the work by analysing the positive values of the dataset to assess the determinants of the abundance of these three vectors and to produce predictive maps of vector abundance.

Methods: Positive counts of the three vectors were assessed using negative-binomial zero-truncated (NBZT) mixed-effect models according to vector control measures and environmental covariates derived from field and remote sensing data. After 8-fold cross-validation of the models, predictive maps of abundance of the sympatric An. funestus, An. coluzzii, and An. gambiae s.s. were produced.

Results: Cross-validation of the NBZT models showed a satisfactory predictive accuracy. Almost all changes in abundance between two surveys in the same village were well predicted by the models but abundances for An. gambiae s.s. were slightly underestimated. During the dry season, predictive maps showed that abundance greater than 1 bite per person per night were observed only for An. funestus and An. coluzzii. During the rainy season, we observed both increase and decrease in abundance of An. funestus, which are dependent on the ecological setting. Abundances of both An. coluzzii and An. gambiae s.s. increased during the rainy season but not in the same areas.

Conclusions: Our models helped characterize the ecological preferences of three major African malaria vectors. This works highlighted the importance to study independently the binomial and the zero-truncated count processes when evaluating vector control strategies. The study of the bio-ecology of malaria vector species in time and space is critical for the implementation of timely and efficient vector control strategies.
\end{abstract}

Keywords: Malaria, Anopheles, Modelling, Abundance, Zero-truncated, Vector control, Map

\section{Background}

The diversity of malaria vector populations, expressing various resistance and/or behavioural patterns is suspected to be involved in the reduction of effectiveness of vector control interventions reported in some African countries [1-3]. A better understanding of the bio-ecology and spatio-temporal distribution of malaria vectors is essential

\footnotetext{
* Correspondence: nicolas.moiroux@ird.fr

'MIVEGEC (IRD 224-CNRS 5290-UM1-UM2), Institut de Recherche pour le Développement (IRD), BP64501, 34394 Montpellier, France

Full list of author information is available at the end of the article
}

to design more effective and sustainable strategies for malaria control and elimination [4-6].

Counts of vectors are often characterized by an excess of zeros due to the absence of vectors at some locations or during some periods of time [7]. From a statistical point of view, these data can be considered as zero-inflated when the number of zeros is higher than that expected under the Poisson or negative binomial distribution assumption. Among methods used to deal with such zero-inflated data [8], hurdle models consider the data responding to two processes: one causing zero versus 
non-zero (i.e. presence $v s$. absence, to analyse with a binomial model) and the second process explaining the non-zero counts (or positive counts, to analyse with a zero-truncated model) [9]. From an ecological point of view, it is relevant to consider these two processes independently because determinants of the presence of a vector can be different from those of its abundance as observed for malaria vector larvae $[10,11]$.

In a previous study, we analyzed presence-absence data (binomial analysis) of An. funestus, An. coluzzii (former M molecular form of An. gambiae s.s. [12]), and An. gambiae s.s. (former S molecular form of $A n$. gambiae s.s.) in an area with high coverage of vector control measures [13]. Here, we used positive values of the dataset (i.e. only when at least one vector was collected) to assess the determinants of the abundance of these three vectors when their presence was confirmed and to produce predictive maps. Then, we discussed similarities and differences between the environmental determinants of presence-absence (previous binomial models) and of abundance (the zero-truncated models produced here) to assess the pertinence of using this two-stage procedure.

\section{Methods}

This study was carried out in 19 villages of the Ouidah-Kpomassè-Tori Bossito (OKT) health administrative region in southern Benin (on the Atlantic coast). Mosquitoes were collected every six weeks during the year 2009 (eight surveys) using the human landing catch (HLC) technique $[14,15]$. HLC were carried out from 22:00 to 06:00 both indoors and outdoors in four houses per village during two successive nights for each survey (i.e., 16 collector-nights per village per survey). Malaria vectors collected on humans were identified using morphological keys [16,17]. All mosquitoes belonging to the Gambiae complex and the Funestus Group were identified to species by PCR $[18,19]$. An. coluzzii and An. gambiae s.s. were identified by the method of Favia et al. [20].

Positive counts of An. funestus, An. coluzzii, and An. gambiae s.s. were assessed according to a set of environmental covariates using a negative-binomial zero-truncated (NBZT) mixed-effect model with nested random effects at the village and house levels. Environmental data used for the analysis are summarised in Table 1. Their definitions, sources and methods of production have been fully described in Moiroux et al. [13]. All covariates act at the village level except the distance from the collection houses to the village perimeter (house level). Meteorological data (rainfall, temperature), Normalized Difference Vegetation Index (NDVI), terrain data (elevation, slope, count of sinks, theoretical flow accumulation), land cover data, and soil data derived from satellite images or maps were averaged in a $2-\mathrm{km}$ radius buffer zone defined around each village. The distance of two kilometres was selected as the radius of the buffer zone because it is the maximum flight range for Anopheles $s p$. and breeding sites located beyond that distance can be considered as insignificant [21]. We chose to study the rainfall that occurred during the 16 days preceding the collections. We can consider that this period greatly influences the development of mosquito larvae and thus the density of adults. Indeed, on the basis of a daily survival rate of $\mathrm{p}=0.9$ [2], we can consider that at least $81 \%$ of mosquitoes collected during each survey emerged during the previous 16 days. This is the result of the ratio of the number of mosquitoes of $<16$ days old to the number of mosquitoes of $<35$ days old surviving until the collection day. This calculation is a ratio of sums of geometric progressions given by the following simplified formula: $\left(1-\mathrm{p}^{16}\right) /\left(1-\mathrm{p}^{35}\right)$ (with the assumption that the number of vectors emerging every day is constant and the fraction surviving more than 35 days is null). Domestic breeding site data and covariates describing attractiveness and penetrability for malaria vectors (number of neighborhoods, population density, distance from the collection houses to the perimeter, and spin and depth indices) were produced at the village perimeter scale. Village perimeters were extracted by on screen digitalization using visual interpretation of the Satellite Pour l'Observation de la Terre (SPOT) image used to produce the land cover map [13].

We used the ' $R$ ' software [22] and the additional 'glmmADMB' [23] package for the analysis. The selection process of the covariates was the same as that described in [13]: (1) univariate selection of the continuous and stratified covariates, (2) analysis of collinearity, and (3) backward selection of the selected covariates in multivariate models. The models were adjusted for the vector control intervention and the collector's position (indoor or outdoor).

The structure of the final multivariate models was evaluated by 8 -fold cross-validation with the data of each survey successively used for validation. The procedure involves (1) re-fitting the selected statistical models to a subset of the dataset which excludes, in turn, data from each of the 8 surveys (training data), and (2) comparing the predictions of the model to each of the excluded datasets (validation data). Our model's ability to estimate the spatiotemporal pattern of malaria vector abundance was assessed by graphically comparing the model predictions to the observed number of Anopheles. Moreover, to compare the predictive performance of our models, we calculated the relative error of the predictions (REP) in each village during each survey. The relative error of prediction was calculated as $R E P=\mid O b s-$ Pred $\mid / O b s$ with Pred the predicted value 
Table 1 Summary of environmental covariates used and species for which these covariates were correlated in the previous binomial analysis

\begin{tabular}{lccc}
\hline Environmental covariates * & Sources & $\begin{array}{c}\text { Area of } \\
\text { measurement }+\dagger\end{array}$ & $\begin{array}{c}\text { Species for which the covariate } \\
\text { has a significant effect in the binomial models [13] }\end{array}$ \\
\hline $\begin{array}{l}\text { Vector control interventions (TLLIN, } \\
\text { ULLIN, ULLIN + CTPS, or TLLIN + IRS) }\end{array}$ & [2] & Village perimeter & An. funestus, An. coluzzii, and An. gambiae S.S. \\
$\begin{array}{l}\text { Number of domestic breeding sites } \\
\text { positives for Anopheles larvae per }\end{array}$ & Systematic inventory [13] & Village perimeter (t) & An. coluzzii and An. gambiae s.S.
\end{tabular}
positives for Anopheles larvae per 100 houses

Mean nocturnal temperatures ${ }^{\ddagger}$

Mean diurnal temperature ${ }^{\ddagger}$

Mean Normalized Difference Vegetation Index (NDVI) ${ }^{\S}$

Cumulated rainfall

Number of rainy days

Mean elevation

Mean slope

Count of sink

Theoretical flow accumulation

Area of hydromorphic soils

Area of each land-cover class**

Edge densities of each land-cover class $^{* *}$

Number of patches of each landcover class**

Patch richness density of land-cover

Simpson's diversity index of land-cover

Modified Simpson's evenness index of land-cover

Length of roads

Number of neighbourhoods

Population density

Distance to the village perimeter

Normalized Spin index of the village shape

Normalized Depth index of the village shape

Number of cattle 8-days Land Surface Temperature (LST) from the MODIS satellite [13]

$$
\begin{aligned}
& \text { 8-days LST from the MODIS } \\
& \text { satellite [13] } \\
& \text { 16-days NDVI from the MODIS } \\
& \text { satellite [13] } \\
& \text { Daily TRMM (3B42) satellite } \\
& \text { data [13] }
\end{aligned}
$$

Daily TRMM satellite data [13]

SPOT Digital Elevation Model (DEM) [13]

SPOT satellite DEM [13]

SPOT DEM [13]

SPOT DEM [13]

Soil map [13]

Land-cover map [13] and systematic inventory

Land-cover map [13] and systematic inventory

Land-cover map [13] and systematic inventory

Land-cover map [13] and systematic inventory

Land-cover map [13] and systematic inventory

Land-cover map [13] and systematic inventory

SPOT satellite image [13]

SPOT image [13]

Systematic inventory [2]

Houses of collection GPS coordinates

SPOT image [13]

SPOT image [13] 2-km buffer (t)

2-km buffer (t)

2-km buffer (t)

2-km buffer (t)

2-km buffer (t)

2-km buffer

2-km buffer

2-km buffer

2-km buffer

2-km buffer

2-km buffer

2-km buffer

2-km buffer

2-km buffer

2-km buffer

2-km buffer

2-km buffer

Village perimeter

Village perimeter

Village perimeter

Village perimeter

Village perimeter
An. funestus, An. coluzzii, and An. gambiae s.s.

An. funestus and An. coluzzii

An. funestus, An. coluzzii, and An. gambiae s.s.

An. funestus, An. coluzzii, and An. gambiae s.s.

$$
\text { An. coluzzii }
$$

An. gambiae s.s.

An. gambiae s.S.

An. funestus and An. coluzzii

An. funestus and An. coluzzii

An. coluzzii and An. gambiae s.s.

An. gambiae s.S

An. funestus and An. coluzzii

Systematic inventory [13] $2-\mathrm{km}$ buffer
An. gambiae s.S.

*Definitions of the environmental variables, sources and methods used to produce them have been fully described in Moiroux et al. [13].

${ }^{\dagger}$ TLLIN: Targeted distribution of Long-Lasting Insecticidal Nets (to children under 6 and pregnant women; class of reference), ULLIN: Universal distribution of LLIN, CTPS: Carbamate Treated Plastic Sheeting, IRS: carbamate Indoor Residual Spraying.

${ }^{\ddagger}$ Mean temperature measured during the week of the catch and both weeks preceding the week of the catch. ${ }^{\S}$ average $16-$ day NDVI during the two-week period including the catch and the preceding 2-week period.

"During the 16 days preceding the catch.

${ }^{* *}$ Calculated for each of the 15 land-cover classes (surface freshwater, aquatic grassland, herb swamp, coco tree, eucalyptus tree, palm tree, teak tree, pineapple, rain fed agriculture, forest, degraded riparian forest, thicket, savannah, market gardening, and degraded surface) and for each of the four strata classes (unvegetated, herbaceous, shrub, and tree).

${ }^{+\dagger}(\mathrm{t})$ : the covariate has a temporal dimension; 2-km buffer: $2-\mathrm{km}$ radius buffer area around the village centre. 
and Obs the observed number of Anopheles collected in the field [24].

Based on the final multivariate NBZT models, two seasonal maps of abundance of the three species were computed for the 15/01/2009 (dry season) and the 30/06/2009 (rainy season) that reflected the meteorological extrema of the year 2009. Indeed, in our study area during 2009, the $15 / 01 / 2009$ and 30/06/2009 followed the 16 days with the minimum $(4 \mathrm{~mm})$ and maximum $(190 \mathrm{~mm})$ mean cumulated rainfall, respectively. Covariates for which data were not available at all points of the area were set at a constant value equal to the mean calculated for overall villages. Abundance predictions were produced only in areas of high probability of presence of the vectors according to the binomial models performed in our previous study [13]. Probability threshold of $0.13,0.21$, and 0.12 were used for An. funestus, An. coluzzii, and An. gambiae s.s. respectively. These thresholds were those maximising specificity and sensitivity of the binomial models (see [13] for details). We can consider that a vector species was absent in areas where the probability of presence was below this threshold. Producing abundance predictions in these areas was therefore irrelevant.

\section{Ethics statement}

The IRD (Institut de Recherche pour le Développement) Ethics Committee and the National Research Ethics Committee of Benin approved the study (CNPERS, reference number IRB00006860). All necessary permits were obtained for the described field studies. No mosquito collection was carried out without the approval of the head of the village, the owner and occupants of the collection house. Mosquito collectors gave their written informed consent and were treated free of charge for malaria presumed illness throughout the study.

\section{Results}

In the 19 villages during 2,432 human-nights of collection, 2,379 malaria vectors were collected: 1,091 were $A n$. funestus, 1,063 were An. coluzzii, and 225 were An. gambiae s.s..
Over 1,216 catches (two human-nights per site per survey), 252, 323, and 114 were positive for An. funestus, $A n$. coluzzii, and An. gambiae s.s., respectively and were used for the NBZT analysis. An. funestus, An. coluzzii, and $A n$. gambiae s.s. were collected in 15, 19, and 17 of the 19 villages, respectively. Details about entomological data (spatial coordinates of the villages, proportion of catch positives for each species, and numbers of vectors collected per villages) are available in [13].

Covariates that were kept in the final multivariate NBZT models, their incidence rate-ratios and 95\% confidence intervals are presented in Table 2 (An. funestus), Table 3 (An. coluzzii), and Table 4 (An. gambiae s.s.). Abundance of $A n$. funestus was positively correlated with the presence of aquatic grassland and cumulated rainfall during the 16 days preceding the catch but negatively correlated with the Normalized Difference Vegetation Index (NDVI). Abundance of An. coluzzii was positively correlated with the nocturnal temperatures recorded during the larval period ( 2 weeks before the catch), cumulated rainfall, and the presence of herb swamp but negatively correlated with the edge density of both aquatic grassland and herbaceous stratum vegetation, the number of patches of freshwater, and the presence of domestic breeding sites positive for Anopheles sp. larvae. Abundance of $A n$. gambiae s.s. was positively correlated with the density of domestic breeding sites positive for Anopheles sp. larvae, the number of cattle, and the elevation but negatively correlated with nocturnal temperatures recorded during the period of the catch.

Abundance of $A n$. coluzzii was higher outdoors, whereas that of An. gambiae s.s. was higher indoors. Abundance of $A n$. funestus was lower in villages that received a universal coverage of Long-Lasting Insecticidal Nets (LLIN) in combination with carbamate treated plastic sheeting (CTPS) than in villages having received a targeted coverage with LLIN (TLLIN). Abundance of An. coluzzii was lower in villages that received a universal coverage with LLINs (ULLIN) than in villages having received a targeted coverage with LLIN (TLLIN).

Table 2 Multivariate zero-truncated mixed-effect model of the abundance of An. funestus

\begin{tabular}{|c|c|c|c|c|c|c|}
\hline \multirow{2}{*}{$\overline{N D V I} 2$ weeks before catch } & & \multirow{2}{*}{$\frac{\text { IRR }}{0.000}$} & \multicolumn{2}{|c|}{$95 \% \mathrm{Cl}$} & \multirow{2}{*}{$\begin{array}{r}\text { P-value } \\
1.22 \mathrm{e}-02\end{array}$} & \multirow[b]{2}{*}{ * } \\
\hline & & & 0.000 & 0.135 & & \\
\hline \multicolumn{2}{|c|}{ Cumulated precipitation 16 days preceding the catch (per additional $\mathrm{mm}$ ) } & 1.006 & 1.001 & 1.011 & $2.89 \mathrm{e}-02$ & * \\
\hline \multirow[t]{2}{*}{ Aquatic grassland } & Absence & 1 & & & & \\
\hline & Presence & 4.713 & 2.179 & 10.194 & $8.20 \mathrm{e}-05$ & *** \\
\hline \multirow[t]{4}{*}{ Vector control intervention } & TLLIN & 1 & & & & \\
\hline & ULLIN & 0.605 & 0.334 & 1.097 & $9.80 \mathrm{e}-02$ & \\
\hline & ULLIN + CTPS & 0.168 & 0.056 & 0.504 & $1.40 \mathrm{e}-03$ & $* *$ \\
\hline & TLLIN + IRS & 0.447 & 0.168 & 1.189 & $1.07 e-01$ & \\
\hline
\end{tabular}

IRR: Incidence rate-ratio; Cl: Confidence Interval; mm: millimetres; TLLIN: Targeted distribution of Long-Lasting Insecticidal Nets; ULLIN: Universal distribution of LLIN; CTPS: Carbamate Treated Plastic Sheeting; IRS: carbamate Indoor Residual Spraying. ${ }^{*} \mathrm{p}<.05 ;{ }^{* *} \mathrm{p}<.01 ;{ }^{* * *} \mathrm{p}<.001$. 
Table 3 Multivariate zero-truncated mixed-effect model of the abundance of An. coluzzii

\begin{tabular}{|c|c|c|c|c|c|c|}
\hline \multirow{2}{*}{\multicolumn{2}{|c|}{ Edge density of aquatic grassland (per additional m/ha) }} & \multirow{2}{*}{$\begin{array}{c}\text { IRR } \\
0.912\end{array}$} & \multicolumn{2}{|c|}{$95 \% \mathrm{Cl}$} & \multirow{2}{*}{$\frac{\text { P-value }}{4.44 \mathrm{e}-03}$} & \multirow[b]{2}{*}{ ** } \\
\hline & & & 0.856 & 0.972 & & \\
\hline \multicolumn{2}{|c|}{ Number of patches of surface freshwater (per additional patch) } & 0.533 & 0.289 & 0.982 & $4.35 \mathrm{e}-02$ & * \\
\hline \multicolumn{2}{|c|}{ Edge density of herb stratum areas (per additional m/ha) } & 0.969 & 0.954 & 0.985 & $1.60 \mathrm{e}-04$ & *** \\
\hline \multicolumn{2}{|c|}{ Nocturnal temperature 2 weeks before the catch (per additional ${ }^{\circ} \mathrm{C}$ ) } & 1.186 & 1.042 & 1.350 & $1.00 \mathrm{e}-02$ & * \\
\hline \multicolumn{2}{|c|}{ Cumulated precipitation 16 days preceding the catch (per additional $\mathrm{mm}$ ) } & 1.008 & 1.006 & 1.010 & $5.30 \mathrm{e}-13$ & *** \\
\hline \multicolumn{2}{|c|}{ Number of breeding sites per 100 houses (per additional site) } & 0.911 & 0.858 & 0.968 & $2.60 \mathrm{e}-03$ & ** \\
\hline \multirow[t]{2}{*}{ Herb swamp } & Absence & 1 & & & & \\
\hline & Presence & 2.569 & 1.147 & 5.753 & $2.18 \mathrm{e}-02$ & * \\
\hline \multirow[t]{4}{*}{ Vector control intervention } & TLLIN & 1 & & & & \\
\hline & ULLIN & 0.390 & 0.159 & 0.955 & $3.93 e-02$ & * \\
\hline & ULLIN + CTPS & 0.824 & 0.301 & 2.255 & $7.07 \mathrm{e}-01$ & \\
\hline & TLLIN + IRS & 1.076 & 0.411 & 2.813 & $8.82 \mathrm{e}-01$ & \\
\hline \multirow[t]{2}{*}{ Collection site } & Indoor & 1 & & & & \\
\hline & Outdoor & 1.416 & 1.021 & 1.963 & $3.71 e-02$ & * \\
\hline
\end{tabular}

IRR: Incidence rate-ratio; $\mathrm{Cl}$ : Confidence Interval; ${ }^{\circ} \mathrm{C}$ : degrees Celsius; $\mathrm{mm}$ : millimetres; m: metres; ha: hectare; TLLIN: Targeted distribution of Long-Lasting Insecticidal Nets; ULLIN: Universal distribution of LLIN; CTPS: Carbamate Treated Plastic Sheeting; IRS: carbamate Indoor Residual Spraying. ${ }^{*} \mathrm{p}<.05 ;{ }^{* *} \mathrm{p}<.01 ;{ }^{* * *} \mathrm{p}<.001$.

Figure 1 shows the distribution of the relative error of prediction against the observed counts of Anopheles. We observed that the prediction error tended to be lower for lower number of vectors collected. The error distributions and hence the predictive powers of the three models were highly comparable. Figure 2 compares the predicted counts to the observed counts for the three species in each village during each survey. The $A n$. funestus (Figure 2A) and An. coluzzii (Figure 2B) models were very efficient in predicting counts. Although the $A n$. gambiae s.s. model (Figure 2C) reflected the trends well, it often underestimated counts.

Maps of the predicted abundance of $A n$. funestus, $A n$. coluzzi, and An. gambiae s.s. during one night of the dry and the rainy season are presented in Figure 3. During the dry season, predicted abundances higher than 1 bite per person per night were observed only for An. funestus (Figure 3A) and $A n$. coluzzii (Figure 3C) but in very limited areas for the latter. During the rainy season, we observed an increase or decrease in predicted abundance of $A n$. funestus depending on the area considered (Figure 3B). Higher predicted abundances of this species ( $>3$ bites/person/night) were observed at the confluence of the arms of the Toho Lake and along this lake's easternmost arm. We observed an increase in predicted abundance of both An. coluzzii and An. gambiae s. $s$. during the rainy season (Figure $3 \mathrm{D}$ and F). Higher predicted abundances of $A n$. coluzzii were found in several restricted areas located between the arms of the Toho Lake, at the border of areas with high probability of

Table 4 Multivariate zero-truncated mixed-effect model of the abundance of An. gambiae s.s

\begin{tabular}{|c|c|c|c|c|c|c|}
\hline \multirow{2}{*}{\multicolumn{2}{|c|}{ Nocturnal temperature the week of the catch (per additional ${ }^{\circ} \mathrm{C}$ ) }} & \multirow{2}{*}{\begin{tabular}{c|} 
IRR \\
0.458
\end{tabular}} & \multicolumn{2}{|c|}{$95 \% \mathrm{Cl}$} & \multicolumn{2}{|l|}{ P-value } \\
\hline & & & 0.283 & 0.741 & $1.44 \mathrm{e}-03$ & $* *$ \\
\hline \multicolumn{2}{|c|}{ Number of breeding sites per 100 houses (per additional site) } & 1.255 & 1.086 & 1.450 & $2.10 \mathrm{e}-03$ & ** \\
\hline \multicolumn{2}{|l|}{ NDVI 2 weeks before catch } & 0.001 & 0.000 & 1.070 & 0.052 & . \\
\hline \multicolumn{2}{|c|}{ Number of cattle (per additional individual) } & 1.021 & 1.004 & 1.039 & $1.51 \mathrm{e}-02$ & * \\
\hline \multicolumn{2}{|l|}{ Elevation (per additional m) } & 1.079 & 1.033 & 1.127 & $5.80 \mathrm{e}-04$ & $* * *$ \\
\hline \multirow[t]{4}{*}{ Vector control intervention } & TLLIN & 1 & & & & \\
\hline & ULLIN & 4.828 & 0.982 & 23.752 & $5.27 e-02$ & . \\
\hline & ULLIN + CTPS & 1.040 & 0.173 & 6.274 & $9.66 \mathrm{e}-01$ & \\
\hline & TLLIN + IRS & 0.499 & 0.118 & 2.108 & $3.44 \mathrm{e}-01$ & \\
\hline \multirow[t]{2}{*}{ Collection site } & Indoor & 1 & & & & \\
\hline & Outdoor & 0.517 & 0.304 & 0.882 & $1.54 \mathrm{e}-02$ & $*$ \\
\hline
\end{tabular}


Figure 1 Distribution of the Relative Error of Predictions (REP) of positive abundances of (A) An. funestus, (B) An. coluzzii, and (C) An. gambiae s.s. The relative error of the predictions (REP) in each village during each survey was calculated as REP $=\mid$ Obs - Pred $\mid$ Obs with Pred the predicted value and Obs the observed number of Anopheles collected in the field. Boxes indicate median, 1st and the 3rd quartiles. Whiskers indicate the most extreme data that is no more than 1.5 times the interquartile range. Outliers are not showed.

presence of this vector. Higher predicted abundances of An. gambiae s.s. were located in the northern part of the study area.

\section{Discussion}

Positive counts of An. funestus, An. coluzzii, and $A n$. gambiae s.s. were assessed according to a set of environmental covariates. As shown in Figure 2, cross-validation of the NBZT models showed a satisfactory predictive accuracy. Most of the time, changes (increase or decrease) in abundance between two surveys in the same village were well predicted by the models with, however, underestimated abundances for An. gambiae s.s. most probably due to a limited sample size [13].

Cumulated rainfall was positively correlated with the abundance of An. funestus and An. coluzzii confirming previous results from our binomial analysis [13]. However, we did not find any relationship between the abundance of An. gambiae s.s. and cumulated rainfall although this variable was previously found to be a predictor of its presence [13]. This may indicate that when the conditions were met for the presence of $A n$. gambiae s.s., additional rainfall did not allow higher numbers of breeding sites or larval production.

Abundance of An. funestus was positively correlated with the presence of aquatic grassland which can favour the larval development of this species [25]. Moreover, the negative relationship between the abundance of $A n$. funestus and the NDVI might indicate that the species was positively correlated to non-permanent aquatic environments since temporary freshwater may decrease the NDVI [26]. Such areas of temporary freshwater may not have been discriminated when classifying the SPOT satellite image as it was acquired during the dry season.

Abundance of An. coluzzii increased in the presence of herb swamps that are temporary flooded environments. In contrast, two landscape indicators of permanent wetlands (number of patches of surface freshwater and edge density of aquatic grassland) were negatively correlated with positive counts of $A n$. coluzzii. Predation pressure on $A n$. coluzzii could explain this result because permanent wetlands are more likely to accommodate for predators of mosquito larvae (fish, Notonectidae, Dytiscidae, etc.) [27]. These results confirm the preference of $A n$. coluzzii for 


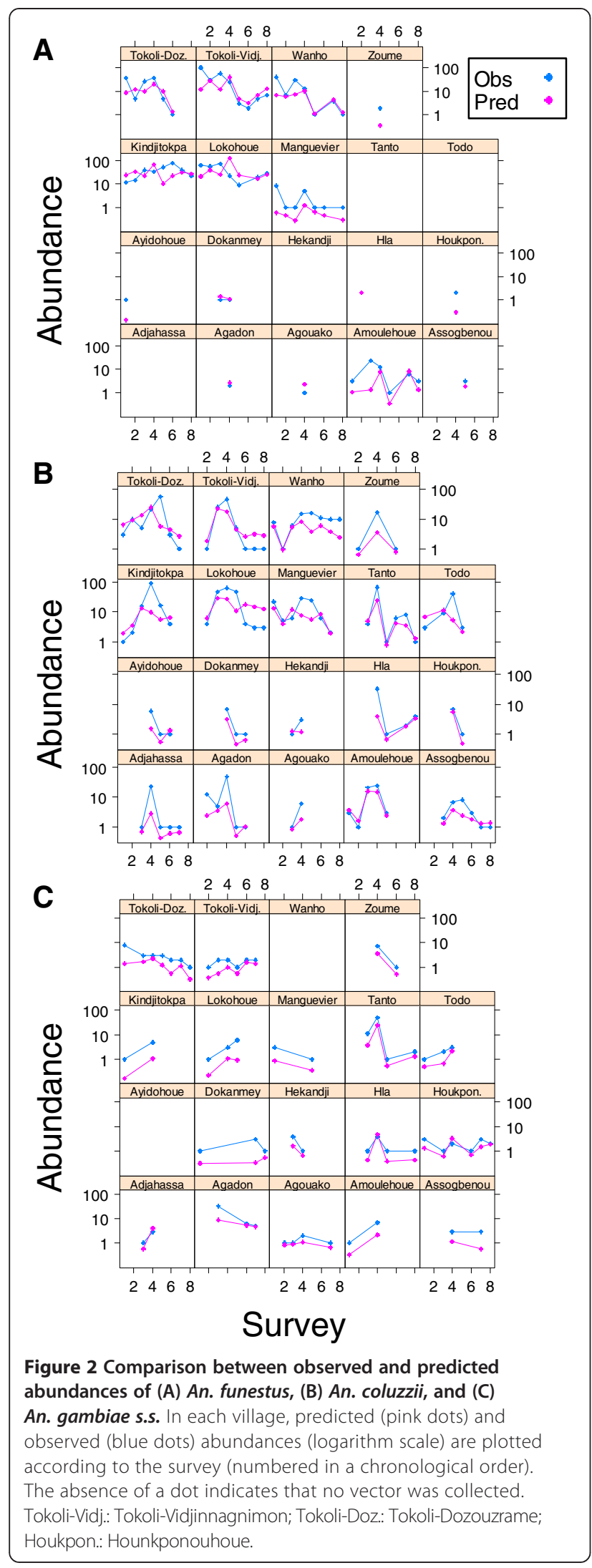

semi-permanent breeding sites as previously observed using a binomial analysis [13].

Although we previously found, using a binomial analysis, that the presence of domestic breeding sites positively correlated with the presence of An. coluzzii [13], this variable was negatively correlated with the abundance here. This might reflect that the presence of these domestic breeding sites (primarily dedicated to water storage) could accommodate for the establishment of this vector but were not very productive. This might be explained by the low development capacity of $A n$. coluz$z i i$ in domestic environments showing regular disturbances (removal of drinking water, cleaning, etc.). On the other hand, abundance of An. gambiae s.s. was positively correlated with the number of domestic breeding sites. Indeed, this vector seems well adapted to such temporary breeding sites thanks to faster larval development rates $[28,29]$.

We also observed a negative correlation between the abundance of An. coluzzii and the edge density of herbaceous landscapes. This observation may reflect a barrier effect of edges between open and closed landscapes against the dispersal of $A n$. Coluzzii, as $84 \%$ of herbaceous landscape edges were common with shrubs or trees strata (data not shown). Indeed, low dispersal distances were previously observed in $A n$. gambiae in forest areas [30]. This difficulty to move in closed landscapes could explain the low vagility of $A n$. coluzzii compared to An. gambiae s.s. as reported in Cameroon [31].

An. gambiae s.s. abundance was negatively correlated with the nocturnal temperatures recorded during the week of the catch. Because people have trouble sleeping under a net on hot nights [32,33], they are more likely to use bednets when nocturnal temperatures are low [34] and fewer hosts are therefore available for vectors. This could result in an over-exposition of the mosquito collectors to An. gambiae s.s. bites when nocturnal temperatures were lower. This phenomenon could be stronger with vector populations resistant to the insecticides used for net impregnation. Indeed, the resistant vectors are more likely to concentrate on available hosts because they could continue to search for a blood meal (instead of dying) after having experienced the contact with a net. This might explain why we were not able to find a similar negative relationship between the nocturnal temperatures and the abundance of both $A n$. funestus and $A n$. coluzzii that are more susceptible to pyrethroid insecticides in the study area $[35,36]$.

Abundance of An. gambiae s.s. was positively correlated with elevation confirming results of the binomial analysis [13]. Indeed, the drier elevated environments could provide ideal rainy dependent breeding sites for this species [27,29]. Hoof prints left by cattle are 


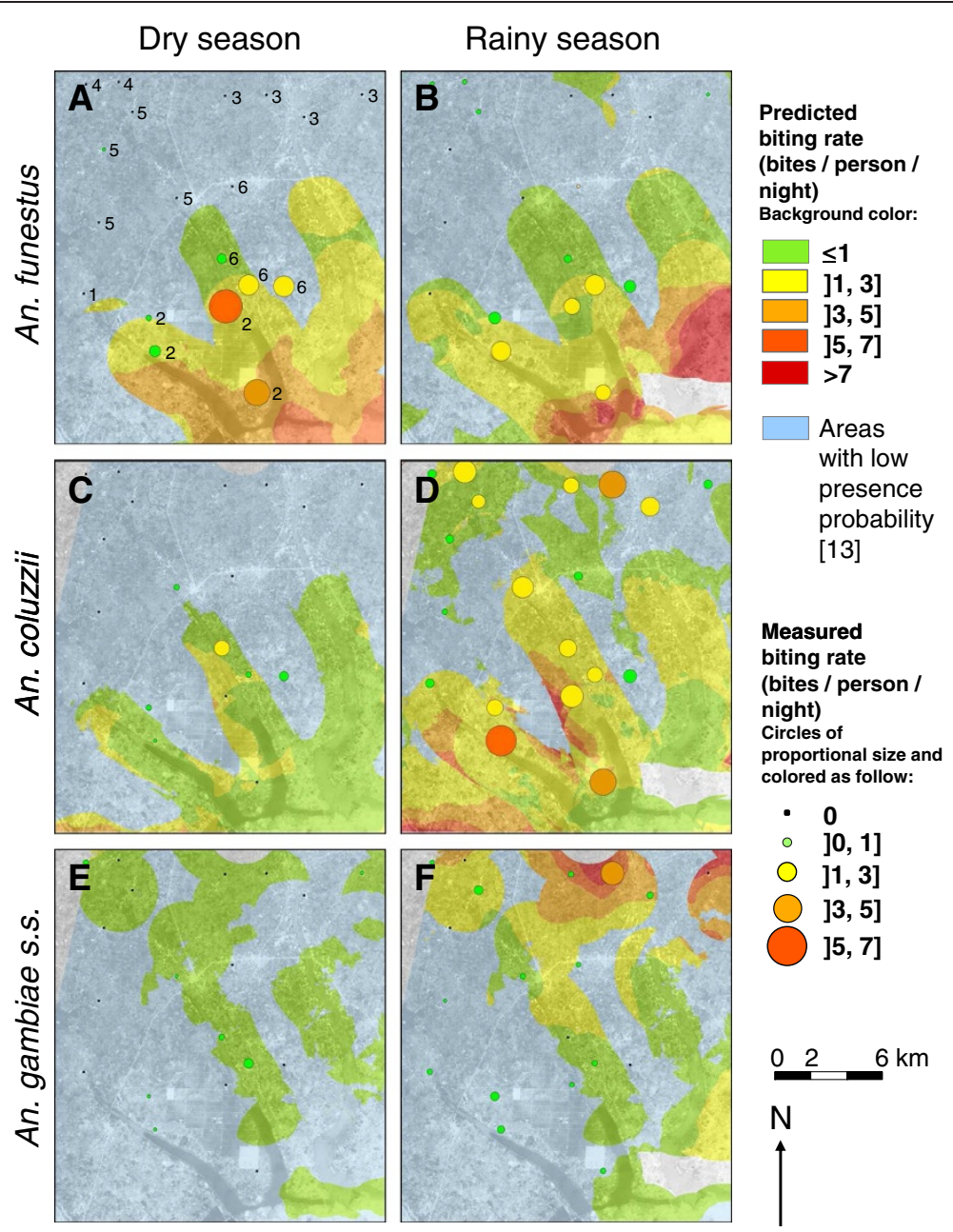

Figure 3 Maps of the predicted abundances of (A, B) An. funestus, (C, D) An. coluzzii, and (E, F) An. gambiae s.s. for one night during the dry and the rainy seasons. Predicted abundance maps were computed based on the final multivariate negative-binomial zero-truncated models. Two seasonal maps of predicted abundance of the three species were computed for the 15/01/2009 (dry season) and the 30/06/2009 (rainy season) that reflected the meteorological extrema of the year 2009. Covariates for which data were not available at all points of the area were set at a constant value equal to the mean calculated for overall villages. Abundance predictions were produced only in areas of high probability of presence of the vectors according to the binomial models performed in [13]. Probability thresholds of $0.13,0.21$, and 0.12 were used for An. funestus, An. coluzzii, and An. gambiae s.s. respectively. These thresholds were those maximising specificity and sensitivity of the binomial models (see [13]). Areas with low probability of presence are coloured in blue in the maps. Measured abundances correspond to data collected during survey 1 (January, dry season) and 4 (June 2009, rainy season). Numbers in panel A refer to the dates of collection in each village with 1: 17/01 and 25/06; 2: 19/01 and 18/06; 3: 22/01 and 23/06; 4: 24/01 and 27/06; 5: 27/01 and 20/06; 6: 29/01 and 16/06. Because predicted and measured abundances are presented for different days, these data should be compared carefully.

also likely to produce temporary breeding sites for Anopheles [37] explaining the positive correlation between the abundance of An. gambiae s.s. and the number of cattle.

Abundance of An. coluzzii was lower in villages that received a universal coverage with LLINs (ULLIN). However, the low significance of this result $(\mathrm{p}=0.04)$ and inconsistence with the result of the binomial analysis [13] does not allow us to conclude on the benefits of the ULLIN strategy. In contrast, abundance of An. funestus was significantly lower in villages that received the ULLIN + CTPS combination when compared with the TLLIN villages, confirming the result of the binomial analysis [13]. Abundance of An. gambiae s.s. was higher in villages that received the ULLIN strategy. Despite the low significance of the relationship ( $\mathrm{p}=0.053)$, this is consistent with the binomial analysis [13]. This could result in the overexposure of mosquito collectors to the vector bite in a context of high levels of LLIN use [13].

Our zero-truncated analysis showed that a greater number of An. gambiae s.s. were collected indoors. However, we showed in a previous study that this vector was more 
likely to be collected outdoors [13]. These results could indicate that the endophagous fraction of the An. gambiae s.s. population concentrated in some houses. This could be due to house designs that favour mosquito entry [38,39]. Conversely, abundance of An. coluzzii was higher outdoors, revealing a mostly exophagous behaviour that may be a response to the vector control (VC) strategies deployed in the villages as already observed for other malaria vector species [36,40-42].

This work has two minor limitations. First, the univariate screening used as a first stage of the variable selection may produce false positives (i.e. variables that are found to be significant "by chance": type I error). However, because the variables used in this study were hypothesis-driven $[13,43]$, the probability of occurrence of a false positive was low. Moreover, we paid great attention to the biological meaning of the covariates kept through the model selection processes and it is therefore less likely that variables selected "by chance" at the univariate screening step were kept in the final multivariate models. Secondly, two covariates of the final multivariate models were measured only at the scale of the 19 villages of the study, the number of cattle and the number of domestic breeding sites, and were therefore not available for all points of the study area when producing predictive maps. Consequently, the maps produced here do not take into account spatial variations of these variables. This has a limited impact on the interpretation of the ecologies of the three vectors, but ideally, to use the maps for policy planning, these variables should be measured in the field for all remaining villages.

Spatial autocorrelation often occurs in animal count data because of the dispersal range of species and because ecological habitats might be auto-correlated. However, when analyzing the spatial autocorrelation in the standardized residuals of our final models (by plotting spline correlograms [44], see Additional file 1), we were not able to find any autocorrelation whatever the distance lag considered. This indicates that the models successfully accommodated for spatial autocorrelation and no important spatial covariate was forgotten.

\section{Conclusion}

Models developed both here and in our previous work [13] helped to better distinguish between the ecological preferences of the three major African malaria vectors in southern Benin. Indeed, our results suggest that $A n$. funestus, An. coluzzii, and An. gambiae s.s. are distributed along a gradient of persistence of the breeding sites, from permanent to temporary. The presence and abundance of An. funestus were correlated with the presence of permanent aquatic environments confirming the literature $[25,45]$. In contrast, An. gambiae s.s. was clearly linked to environments providing temporary breeding sites, hence confirming other studies $[27,45]$. An. coluzzii seemed to take an intermediate position, being associated with semi-permanent environments. The zero-truncated analysis produced here helped refine these observations since An. funestus and An. coluzzii seemed to prefer vegetated aquatic environments (aquatic grasslands and herb swamps, respectively).

These findings also highlight the importance of studying independently the binomial and the zero-truncated count processes when evaluating VC strategies. The separate study of the determinants of presence and abundance should be encouraged as it enables discrimination between areas and periods (using seasonal maps of vector's presence and abundance) to be targeted in priority by $\mathrm{VC}$ (in relation to the vectors' ecologies). These research efforts on the biology and ecology of malaria vectors are important to achieve the WHO and Roll Back Malaria objectives, i.e. $75 \%$ reduction of malaria morbidity and near zero mortality by 2015 in Africa [46,47].

\section{Additional file}

\section{Additional file 1: Spline correlograms, with $95 \%$ pointwise bootstrap confidence intervals, of the standardized residuals from the final multivariate (A) An. funestus, (B) An. coluzzii, and (C) \\ An. gambiae s.s. models. Spline correlograms [44] were plotted using the 'spline.correlog' function in the 'ncf' package in $R$.}

\section{Competing interests}

The authors declare that they have no competing interests.

\section{Authors' contributions}

NM, VC, FC and HG designed the study. NM, ASB, and AD collected field data. NM treated the data. NM and HG performed the analysis. NM, VC and $\mathrm{HG}$ wrote the article. All authors read and approved the final version of the article

\section{Acknowledgements}

We thank populations of the villages for their kind support and collaboration. We also thank all the field and laboratory staff for their strong commitment to this project. We thank the French ministry of foreign affairs through the SCAC programme and IRD for their financial support. NM thank Mr François Lacoste and Mrs Paule Hamploy for their financial support. This study was partially funded by EU grant FP7-261504 EDENext and is catalogued by the EDENext Steering Committee as Edenext202 (http://www.edenext.eu). The contents of this publication are the sole responsibility of the authors and don't necessarily reflect the views of the European Commission. We thank the ISIS programme of CNES for providing us the SPOT image.

\section{Author details}

${ }^{1}$ MIVEGEC (IRD 224-CNRS 5290-UM1-UM2), Institut de Recherche pour le Développement (IRD), BP64501, 34394 Montpellier, France. ${ }^{2}$ MIVEGEC (IRD 224-CNRS 5290-UM1-UM2), Institut de Recherche pour le Développement (IRD), 01 BP4414 RP, Cotonou, Bénin. ${ }^{3}$ Centre de Recherche en Entomologie de Cotonou (CREC), Ministère de la Santé, Cotonou, Bénin. ${ }^{4}$ Department of Entomology, Faculty of Agriculture, Kasetsart University, Bangkok10900, Thailand. ${ }^{5}$ CIRAD, UMR CMAEE, F-34398 Montpellier, France. ${ }^{6}$ INRA, UMR, 1309 CMAEEF-34398, Montpellier, France.

Received: 17 September 2013 Accepted: 3 March 2014

Published: 12 March 2014 


\section{References}

1. Trape JF, Tall A, Diagne N, Ndiath O, Ly AB, Faye J, Dieye-Ba F, Roucher C, Bouganali C, Badiane A, Sarr FD, Mazenot C, Toure-Balde A, Raoult D, Druilhe P, Mercereau-Puijalon O, Rogier C, Sokhna C: Malaria morbidity and pyrethroid resistance after the introduction of insecticide-treated bednets and artemisinin-based combination therapies: a longitudinal study. Lancet Infect Dis 2011, 11:925-932.

2. Corbel V, Akogbeto M, Damien GB, Djenontin A, Chandre F, Rogier C, Moiroux N, Chabi J, Banganna B, Padonou GG, Henry MC: Combination of malaria vector control interventions in pyrethroid resistance area in Benin: a cluster randomised controlled trial. Lancet Infect Dis 2012 12:617-626.

3. Asidi A, N'Guessan R, Akogbeto M, Curtis C, Rowland M: Loss of household protection from use of insecticide-treated nets against pyrethroid-resistant mosquitoes, benin. Emerg Infect Dis 2012, 18:1101-1106.

4. Ferguson HM, Dornhaus A, Beeche A, Borgemeister C, Gottlieb M, Mulla MS, Gimnig JE, Fish D, Killeen GF: Ecology: a prerequisite for malaria elimination and eradication. PLOS Med 2010, 7:e1000303.

5. The malERA Consultative Group on Vector Control: A research agenda for malaria eradication: vector control. PLOS Med 2011, 8:e1000401.

6. Sinka ME, Bangs MJ, Manquin S, Rubio-Palis Y, Chareonviriyaphap T, Coetzee M Mbogo CM, Hemingway J, Patil AP, Temperley WH, Gething PW, Kabaria CW, Burkot TR, Harbach RE, Hay SI: A global map of dominant malaria vectors. Parasit Vectors 2012, 5:69.

7. Boussari O, Moiroux N, Iwaz J, Djenontin A, Bio-Bangana S, Corbel V, Fonton N, Ecochard R: Use of a mixture statistical model in studying malaria vectors density. PLoS One 2012, 7:e50452.

8. Martin TG, Wintle BA, Rhodes JR, Kuhnert PM, Field SA, Low-Choy SJ, Tyre AJ, Possingham HP: Zero tolerance ecology: improving ecological inference by modelling the source of zero observations. Ecol Lett 2005, 8:1235-1246.

9. Zuur AF, leno EN, Walker NJ, Saveliev AA, Smith GM: Mixed effects models and extensions in ecology with R. New York: Springer; 2009.

10. Bugoro H, Hii J, Russell TL, Cooper RD, Chan BK, Iro'ofa C, Butafa C, Apairamo A, Bobogare A, Chen CC: Influence of environmental factors on the abundance of Anopheles farauti larvae in large brackish water streams in Northern Guadalcanal, Solomon Islands. Malar J 2011, 10:262.

11. Gadiaga L, Machault V, Pages F, Gaye A, Jarjaval F, Godefroy L, Cisse B, Lacaux JP, Sokhna C, Trape JF, Rogier C: Conditions of malaria transmission in Dakar from 2007 to 2010. Malar J 2011, 10:312.

12. Coetzee M, Hunt RH, Wilkerson R, Della Torre A, Coulibaly MB, Besansky NJ: Anopheles coluzzii and Anopheles amharicus, new members of the Anopheles gambiae complex. Zootaxa 2013, 3619:246-274.

13. Moiroux N, Bio-Bangana A, Djenontin A, Chandre F, Corbel V, Guis H: Modelling the risk of being bitten by malaria vectors in a vector control area in southern Benin, West Africa. Parasit Vectors 2013, 6:71.

14. Coffinet T, Rogier C, Pages F: [Evaluation of the anopheline mosquito aggressivity and of malaria transmission risk: methods used in French Army]. Med Trop (Mars) 2009, 69:109-122.

15. Silver JB: Sampling Adults by Animal Bait Catches and by Animal-Baited Traps. In Mosquito Ecology. Dordrecht: Springer; 2008:493-675.

16. Gillies M, Coetzee M: A supplement to the Anophelinae of Africa South of the Sahara (Afrotropical Region). Johannesburg, South Africa: South African Institute for Medical Research; 1987.

17. Gillies M, DeMeillon B: The Anophelinae of Africa South of the Sahara (Ethiopian Zoogeographical Region). Publication South Afr Inst Med Res 1968, 54:343.

18. Koekemoer LL, Kamau L, Hunt RH, Coetzee M: A cocktail polymerase chain reaction assay to identify members of the Anopheles funestus (Diptera: Culicidae) group. Am J Trop Med Hyg 2002, 66:804-811.

19. Scott JA, Brogdon WG, Collins FH: Identification of single specimens of the Anopheles gambiae complex by the polymerase chain reaction. Am J Trop Med Hyg 1993, 49:520-529.

20. Favia G, Lanfrancotti A, Spanos L, Siden-Kiamos I, Louis C: Molecular characterization of ribosomal DNA polymorphisms discriminating among chromosomal forms of Anopheles gambiae s.s. Insect Mol Biol 2001, 10:19-23.

21. Service MW: Mosquito (Diptera: Culicidae) dispersal-the long and short of it. J Med Entomol 1997, 34:579-588.

22. R Development Core Team: R: A Language and Environment for Statistical Computing. 212th edition. Vienna, Austria: R Foundation for Statistical Computing; 2010.
23. Skaug $H$, Fournier D, Nielsen A, Magnusson A, Bolker B: glmmADMB: Generalized Linear Mixed Models Using AD Model Builder; 2012. R package version 0725/r186

24. Cottrell G, Kouwaye B, Pierrat C, le Port A, Bouraima A, Fonton N, Hounkonnou MN, Massougbodji A, Corbel V, Garcia A: Modeling the influence of local environmental factors on malaria transmission in Benin and its implications for cohort study. PLoS One 2012, 7:e28812.

25. Hamon J: Biologie d'Anopheles funestus. In Biologie des anophèles d'AOF et d'AEF, Volume 2. Paris: ORSTOM; 1955. 6 multigr.

26. Tucker CJ: Red and photographic infrared linear combinations for monitoring vegetation. Remote Sens Environ 1979, 8:127-150.

27. Gimonneau G, Pombi M, Choisy M, Morand S, Dabire RK, Simard F: Larval habitat segregation between the molecular forms of the mosquito Anopheles gambiae in a rice field area of Burkina Faso, West Africa. Med Vet Entomol 2011, 26:9-17.

28. Diabate A, Dabire RK, Heidenberger K, Crawford J, Lamp WO, Culler LE, Lehmann T: Evidence for divergent selection between the molecular forms of Anopheles gambiae: role of predation. BMC Evol Biol 2008, 8:5

29. Diabate A, Dabire RK, Kim EH, Dalton R, Millogo N, Baldet T, Simard F, Gimnig JE, Hawley WA, Lehmann T: Larval development of the molecular forms of Anopheles gambiae (Diptera: Culicidae) in different habitats: a transplantation experiment. J Med Entomol 2005, 42:548-553.

30. Le Goff G, Carnevale P, Robert V: Low dispersion of anopheline malaria vectors in the African equatorial forest. Parasite 1997, 4:187-189.

31. Simard F, Ayala D, Kamdem GC, Pombi M, Etouna J, Ose K, Fotsing JM, Fontenille D, Besansky NJ, Costantini C: Ecological niche partitioning between Anopheles gambiae molecular forms in Cameroon: the ecological side of speciation. BMC Ecol 2009, 9:17.

32. Binka FN, Adongo P: Acceptability and use of insecticide impregnated bednets in northern Ghana. Trop Med Int Health 1997, 2:499-507.

33. Frey C, Traore C, De Allegri M, Kouyate B, Muller O: Compliance of young children with ITN protection in rural Burkina Faso. Malar J 2006, 5:70.

34. Moiroux N, Boussari O, Djènontin A, Damien G, Cottrell G, Henry M-C, Guis $H$, Corbel V: Dry season determinants of malaria disease and net use in Benin, West Africa. PLoS One 2012, 7:e30558.

35. Djenontin A, Bio-Bangana S, Moiroux N, Henry MC, Bousari O, Chabi J, Osse R, Koudenoukpo S, Corbel V, Akogbeto M, Chandre F: Culicidae diversity, malaria transmission and insecticide resistance alleles in malaria vectors in Ouidah-Kpomasse-Tori district from Benin (West Africa): A pre-intervention study. Parasit Vectors 2010, 3:83.

36. Moiroux N, Gomez MB, Pennetier C, Elanga E, Djenontin A, Chandre F, Djegbe I, Guis H, Corbel V: Changes in Anopheles funestus biting behavior following universal coverage of long-lasting insecticidal nets in Benin. J Infect Dis 2012, 206:1622-1629.

37. Minakawa N, Mutero CM, Githure JI, Beier JC, Yan G: Spatial distribution and habitat characterization of anopheline mosquito larvae in Western Kenya. Am J Trop Med Hyg 1999, 61:1010-1016.

38. Lindsay SW, Jawara M, Paine K, Pinder M, Walraven GE, Emerson PM: Changes in house design reduce exposure to malaria mosquitoes. Trop Med Int Health 2003, 8:512-517.

39. Lwetoijera D, Kiware S, Mageni Z, Dongus S, Harris C, Devine G, Majambere S: A need for better housing to further reduce indoor malaria transmission in areas with high bed net coverage. Parasit Vectors 2013, 6:57.

40. Reddy M, Overgaard H, Abaga S, Reddy V, Caccone A, Kiszewski A, Slotman M: Outdoor host seeking behaviour of Anopheles gambiae mosquitoes following initiation of malaria vector control on Bioko Island, Equatorial Guinea. Malar J 2011, 10:184.

41. Russell TL, Govella NJ, Azizi S, Drakeley CJ, Kachur SP, Killeen GF: Increased proportions of outdoor feeding among residual malaria vector populations following increased use of insecticide-treated nets in rural Tanzania. Malar J 2011, 10:80.

42. Govella NJ, Ferguson $\mathrm{H}$ : Why use of interventions targeting outdoor biting mosquitoes will be necessary to achieve malaria elimination. Front Physiol 2012, 3:199.

43. Moiroux N: Modélisation du risque d'exposition aux moustiques vecteurs de Plasmodium spp. dans un contexte de lutte anti-vectorielle, PhD thesis. Montpellier: Université Montpellier II-Sciences et Techniques du Languedoc; 2012

44. BjØrnstad O, Falck W: Nonparametric spatial covariance functions: Estimation and testing. Env Ecol Stat 2001, 8:53-70. 
45. Gimnig JE, Ombok M, Kamau L, Hawley WA: Characteristics of larval anopheline (Diptera: Culicidae) habitats in Western Kenya. J Med Entomol 2001, 38:282-288.

46. WHO: World Malaria Report: 2012. Geneva: World Health Organization; 2012:195.

47. Roll Back Malaria Partnership: The global malaria action plan; 2008:274.

doi:10.1186/1756-3305-7-103

Cite this article as: Moiroux et al:: Spatio-temporal analysis of

abundances of three malaria vector species in southern Benin using zero-truncated models. Parasites \& Vectors 2014 7:103.

\section{Submit your next manuscript to BioMed Central} and take full advantage of:

- Convenient online submission

- Thorough peer review

- No space constraints or color figure charges

- Immediate publication on acceptance

- Inclusion in PubMed, CAS, Scopus and Google Scholar

- Research which is freely available for redistribution 